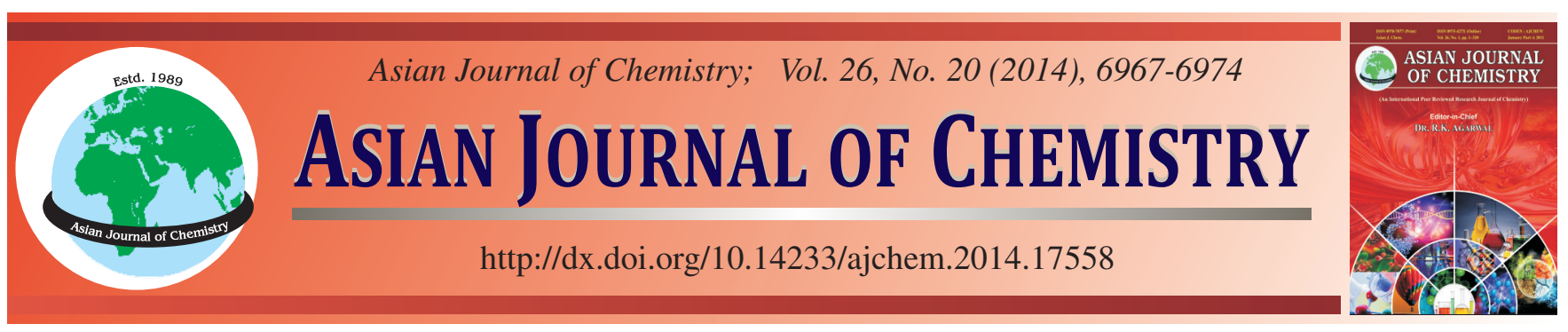

\title{
Response Surface Design for Optimization of Microcystis aeruginosa Removal by Ultrasonic Irradiation
}

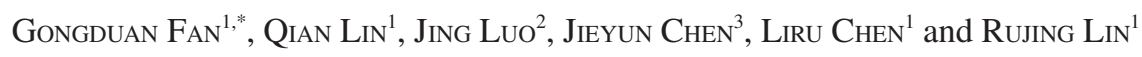

${ }^{1}$ College of Civil Engineering, Fuzhou University, Fuzhou 350108, Fujian Province, P.R. China

${ }^{2}$ Fujian Jinzhongmin Environment Frotection and Energy-saving Engineering Co., Ltd., Fuzhou 350000, Fujian Province, P.R. China

${ }^{3}$ Chongqing Jianlong Environmental Protection Engineering Co., Ltd., Chongqing 400000, P.R. China

*Corresponding author: Fax: +86 591 22865355; Tel: +86 591 22865361; E-mail: fgdfz@fzu.edu.cn

Received: 6 March 2014;

Accepted: 18 April 2014;

Published online: 25 September 2014;

AJC-16049

Major bloom-forming organism is the species Microcystis aeruginosa which produces hepatotoxin microcystin into water and it is harm to aquatic organisms and humans. Ultrasound is an environment-friendly technology and inhibits the growth of algae effectively. First of all, the effect of ultrasonic frequency, power density and irradiation time on Microcystis aeruginosa through single factor experiments was studied. Then the optimized values of the three parameters were determined by Box-Behnken model of response surface design. Results showed that the removal efficiency of chlorophyll-a reached to $(99.33 \pm 0.02) \%$ after sonication for $24 \mathrm{~s}$ at $580 \mathrm{kHz}$ and $0.089 \mathrm{~W} / \mathrm{mL}$. Ultrasonic technology can remove Microcystis aeruginosa in water effectively.

Keywords: Ultrasonic irradiation, Algae removal, Microcystis aeruginosa, Response surface design.

\section{INTRODUCTION}

In the warmer months, blooms of toxic cyanobacteria, periodically occur in eutrophicated water body ${ }^{1}$. The members of the genus Microcystis are the most prevalent cyanobacteria worldwide and the species Microcystis aeruginosa is the major bloom-forming organism ${ }^{2}$. As Microcystis aeruginosa can release hepatotoxin microcystin into water, it harms to aquatic organisms and human ${ }^{3}$. The traditional treatment for the control of the water bloom, including nutrient diversion ${ }^{4}$, artificial destratification, hypolimnetic aeration/withdrawal, sediment oxidation/removal ${ }^{5}$, phosphorus precipitation and biomanipulation $^{2,6}$, are usually expensive, complex and can cause further pollution due to the use of chemicals ${ }^{7}$. Non-chemical treatments are increasingly used in cooling water, wastewater treatment or potable water disinfection ${ }^{8}$.

Sonication is clean and efficient, known as an environment-friendly technology ${ }^{9}$. Ultrasound can lead to structural and functional disruption of cyanobacteria cells through cavitation (i.e., the compression, rarefaction and implosive collapse of bubbles in a liquid ${ }^{10}$. Previous studies have shown that the control parameters such as ultrasonic frequency, ultrasonic power density and ultrasonic irradiation time have a significant impact on the removal of algae $\mathrm{e}^{11-13}$.

Response surface method is an analysis method of condition optimization, with the combination of mathematics and statistics ${ }^{14}$. It considers both test random error and complex relationship among unknown functions fitted with multiple regression equations within a small area. It is a valid method used to optimize conditions, reduce costs, improve product quality and solve actual problems in the production ${ }^{15,16}$. In this paper, ultrasonic frequency, ultrasonic power density and ultrasonic irradiation time are controlling factors to study the influence of ultrasound on the removal of Microcystis aeruginosa. The purpose is selecting a suitable scope for further testing and obtaining the optimum values of control parameters through Box-Behnken model and response surface method, providing theoretical basis for the control of Microcystis aeruginosa blooms in water.

\section{EXPERIMENTAL}

The experimental reactor used in this study was supplied by Institute of Acoustics of the Chinese Academy of Sciences, with other parts were self-made. The experimental setup was shown in Fig. 1. The ultrasound source was an ATANA AT3020 ultrasonic signal generator. The power amplifier with the model HFVA-62 was from Nanjing Foneng Co., Ltd.

Determination of experimental parameters: Ultrasonic frequency and power density were detected by the Ut2025C oscilloscope produced by Unit-Trend group limited in Hong Kong and CS-3A hydrophone produced by the Institute of acoustics, Chinese Academy of Sciences. Aqua Fluor Handheld 


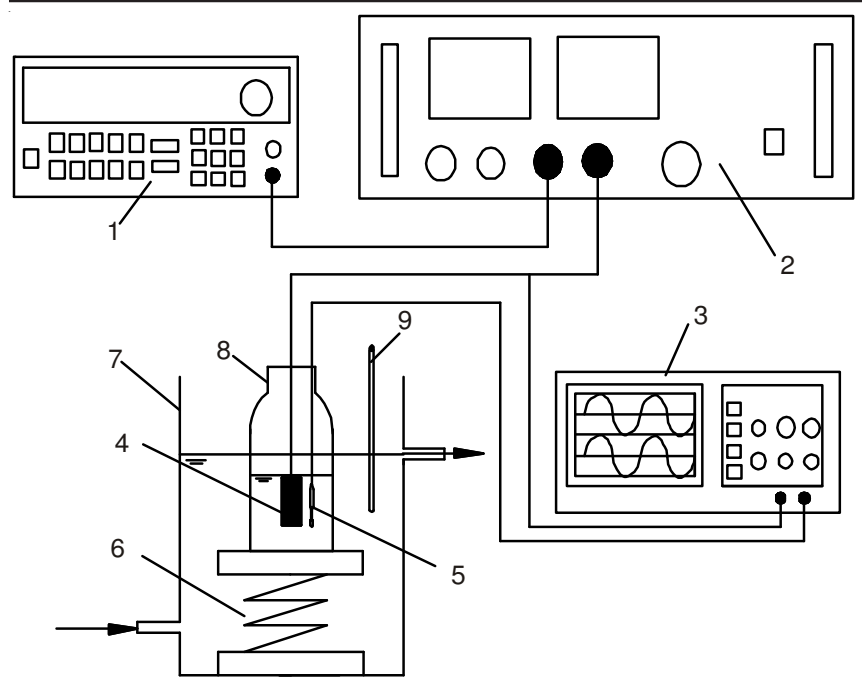

Fig. 1. Experimental apparatus of sonication (1) signal generator; (2) power amplifier; (3) oscilloscope; (4) transducer; (5) hydrophone; (6) telescopic stand; (7) cooling; (8) glass flask; (9) thermometer

Chlorophyll Fluorescence Tester (8000-010) was used to detect Chlorophyll- $a$, which was manufactured by United States Turner Designs.

Algae samples and culture methods: Microcystis aeruginosa was provided by fresh water algae culture collection of the Institute of Hydrobiology of Chinese Academy of Sciences (FACHB-1027). We placed the algae in a constant-light incubator to inactivate the culture. The temperature was set to $25^{\circ} \mathrm{C}$, light intensity to $2000 \mathrm{~lx}$ and the light-dark cycle to $14 \mathrm{~h}$ : $10 \mathrm{~h}$. The algae was initially cultivated in the prepared monoculture BG11, which was provided by the Freshwater Algae Culture Collection of the Institute of Hydrobiology. The volume of the medium was the same with the volume of the algae liquid that used in this experiment. The composition of BG11 was 1.5 $\mathrm{g} / \mathrm{L} \mathrm{NaNO}_{3}, 0.04 \mathrm{~g} / \mathrm{L} \mathrm{K}_{2} \mathrm{HPO}_{4} \cdot 3 \mathrm{H}_{2} \mathrm{O}, 0.075 \mathrm{~g} / \mathrm{L} \mathrm{MgSO}_{4} \cdot 7 \mathrm{H}_{2} \mathrm{O}$, $0.036 \mathrm{~g} / \mathrm{L} \mathrm{CaCl}{ }_{2} \cdot 2 \mathrm{H}_{2} \mathrm{O}, 0.006 \mathrm{~g} / \mathrm{L}$ citric acid, $0.006 \mathrm{~g} / \mathrm{L}$ ferric ammonium citrate, $0.001 \mathrm{~g} / \mathrm{L}$ EDTA, $0.02 \mathrm{~g} / \mathrm{L} \mathrm{Na}_{2} \mathrm{CO}_{3}$ and $1 \mathrm{~mL} / \mathrm{L} \mathrm{A}_{5}+\mathrm{Co}$ solution. The composition of the $\mathrm{A}_{5}+\mathrm{Co}$ solution was $2.86 \mathrm{~g} / \mathrm{L} \mathrm{H}_{3} \mathrm{BO}_{3}, 1.86 \mathrm{~g} / \mathrm{L} \mathrm{MnCl}_{2} \cdot 4 \mathrm{H}_{2} \mathrm{O}, 0.22 \mathrm{~g} / \mathrm{L}$ $\mathrm{ZnSO}_{4} \cdot 7 \mathrm{H}_{2} \mathrm{O}, 0.39 \mathrm{~g} / \mathrm{L} \mathrm{Na}_{2} \mathrm{MoO}_{4} \cdot 2 \mathrm{H}_{2} \mathrm{O}, 0.08 \mathrm{~g} / \mathrm{L} \mathrm{CuSO} \cdot \cdot 5 \mathrm{H}_{2} \mathrm{O}$ and $0.05 \mathrm{~g} / \mathrm{L} \mathrm{Co}\left(\mathrm{NO}_{3}\right)_{2} \cdot 6 \mathrm{H}_{2} \mathrm{O}$. The $\mathrm{pH}$ value of the $\mathrm{BG} 11$ medium was 7.1, which was adjusted using $\mathrm{NaOH}$ or $\mathrm{HCl}$. The algae was cultivated until their density reached approximate $10^{7}$ cells $/ \mathrm{mL}$. At this concentration, the algae liquid can be used for the ultrasonic experiment.

Experimental methods: $800 \mathrm{~mL}$ of algae solution was put into a group of $1 \mathrm{~L}$ beakers. The ultrasonic transducer, which was $30 \mathrm{~mm}$ below the liquid level, irradiated the algae solution at different ultrasonic frequency, power density and irradiation time. After sonication, determined the concentration of Microcystis aeruginosa in supernatant and calculated the removal efficiencies that was assessment index. The expression was shown as eqn. (1).

$$
\text { Removal of Chlorophy }-a=\frac{\mathrm{Chla}_{0}-\mathrm{Chla}_{1}}{\mathrm{Chla}_{0}} \times 100 \%
$$

where $C h l a_{0}$ is the concentration $(\mu \mathrm{g} / \mathrm{L})$ of Chlorophyll-a of Microcystis aeruginosa before ultrasonic treatment, $C h l a_{1}$ is the concentration $(\mu \mathrm{g} / \mathrm{L})$ of Chlorophyll-a after ultrasonic treatment.

\section{RESULTS AND DISCUSSION}

\section{Single factor experiments}

Effect of different ultrasonic power density on Microcystis aeruginosa: Preparing 6 groups of $500 \mathrm{~mL}$ of Microcystis aeruginosa, one group was control group and the others were irradiating respectively at $0.00006,0.0026,0.018,0.0504$ and $0.101 \mathrm{~W} / \mathrm{mL}$ for $5 \mathrm{~min}$. Ultrasonic frequency and temperature were fixed at $500 \mathrm{kHz}$ and $20^{\circ} \mathrm{C}$. Fig. 2 is the changes of the concentration of chlorophyll-a after sonication at ultrasonic power density. Fig. 3 shows the removal efficiencies of Microcystis aeruginosa.

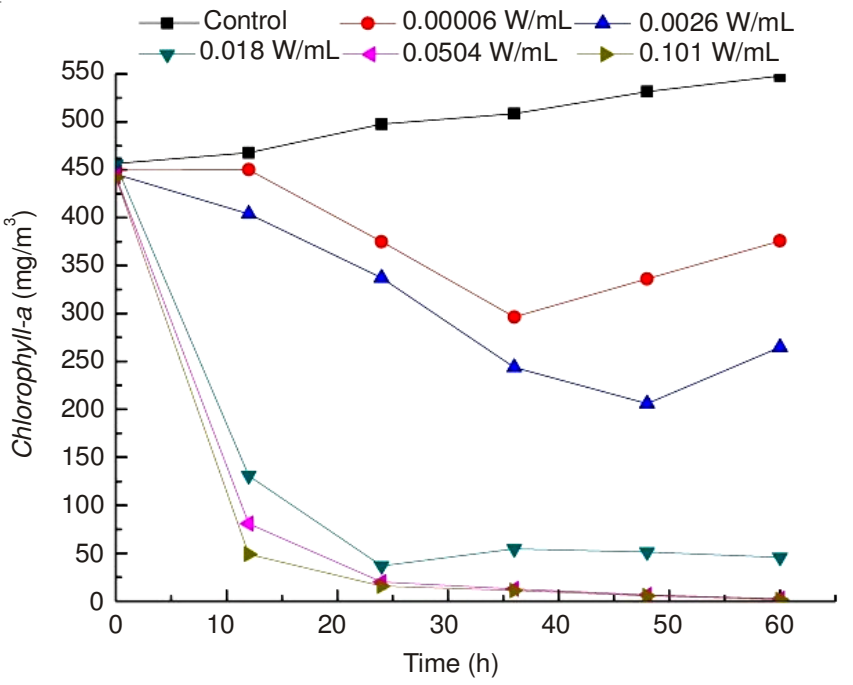

Fig. 2. Changes of the concentration of Chlorophyll-a of Microcystis aeruginosa after sonication at different ultrasonic power density

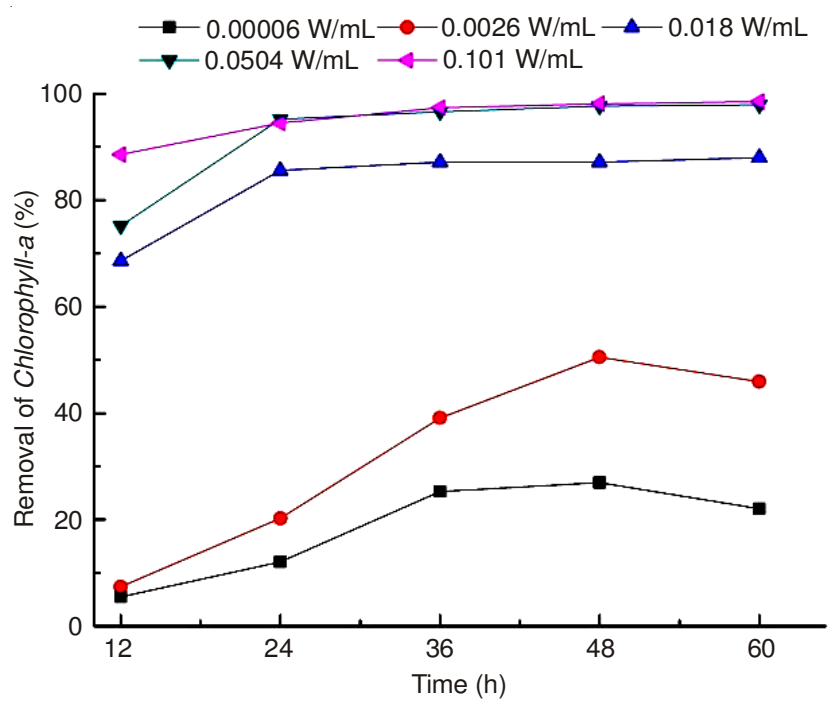

Fig. 3. Removal efficiencies of Microcystis aeruginosa at different ultrasonic power density

In Fig. 3, the efficiency of $0.00006 \mathrm{~W} / \mathrm{mL}$ of sonication was $25.25 \%$ which is relatively small, because lower ultrasonic power density mainly caused mechanical effect that was less destructive. The removal efficiencies increased with the increasing of ultrasonic frequency. While power density was higher than threshold value, removal efficiency rose significantly because of cavitation. 
The difference of removal efficiency between 0.0504 and $0.101 \mathrm{~W} / \mathrm{mL}$ was only $0.76 \%$, which indicated that the effect of ultrasonic power density tended to be saturate, it also can be concluded that cavatition was main effect factor.

Most of the algae cells were settled but not degraded directly, which illustrated that the cells were damaged. Algae cell started to repair automatically after sonication at low power density for $48 \mathrm{~h}$, led to the increase of biomass. However, higher power density caused permanent damage to algae cells and they couldn't repair.

The low power density ultrasound (lower than threshold value) influence algal growth mainly by mechanical action and the effect was modest that the damage can be fixed. However high power density (higher than threshold value) which could cause cavitation and mechanical action. Cavitation was dominant action, can destroy algae cells permanently.

Effect of different ultrasonic irradiation time on Microcystis aeruginosa: Preparing 6 groups of $500 \mathrm{~mL}$ of Microcystis aeruginosa, one group was control group and the others were irradiating, respectively at 2, 5, 10,20 and $30 \mathrm{~min}$. Ultrasonic frequency and temperature were fixed at $500 \mathrm{kHz}$ and $20{ }^{\circ} \mathrm{C}$. Fig. 4 is the changes of the concentration of Chlorophyll- $a$ after sonication at different ultrasonic irradiation time. Fig. 5 shows the removal efficiencies of Microcystis aeruginosa.

In Fig.4, concentrations of living Chlorophyll-a were 11.3, $54.5,64,132.1$ and $184 \mathrm{mg} / \mathrm{m}^{3}$ and control group was 508.5 $\mathrm{mg} / \mathrm{m}^{3}$. Contrast with control group, the concentrations of living Chlorophyll- $a$ of experimental groups all dropped greatly, but the content of living chlorophyll-a of 2 min was smaller than 5, 10, 20 and $30 \mathrm{~min}$, because the longer radiation time, the more broken Microcystin algae, causing more Chlorophyll-a releasing into water. While irradiation time was not too long, sinking rate of chlorophyll a was higher than degradation rate in solution. Therefore, long irradiation time of high intensity ultrasound has negative impacts on the water and is not economical. Setting an appropriate irradiation time should be especially considered in application.

In Fig. 5, the removal efficiency was 85.7, 86.1, 98.1, 98.7 and $99.3 \%$ at the $2,5,10,20$ and 30 min after radiation for $36 \mathrm{~h}$. When time was longer than $2 \mathrm{~min}$, there was little difference in the control efficiencies.

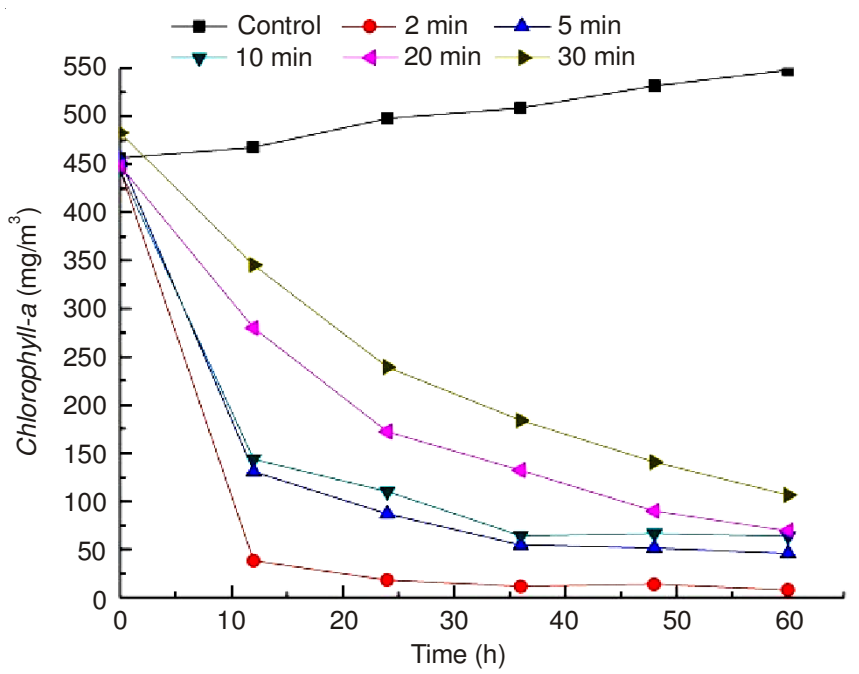

Fig. 4. Changes of the concentration of Chlorophyll-a after sonication at different ultrasonic irradiation time

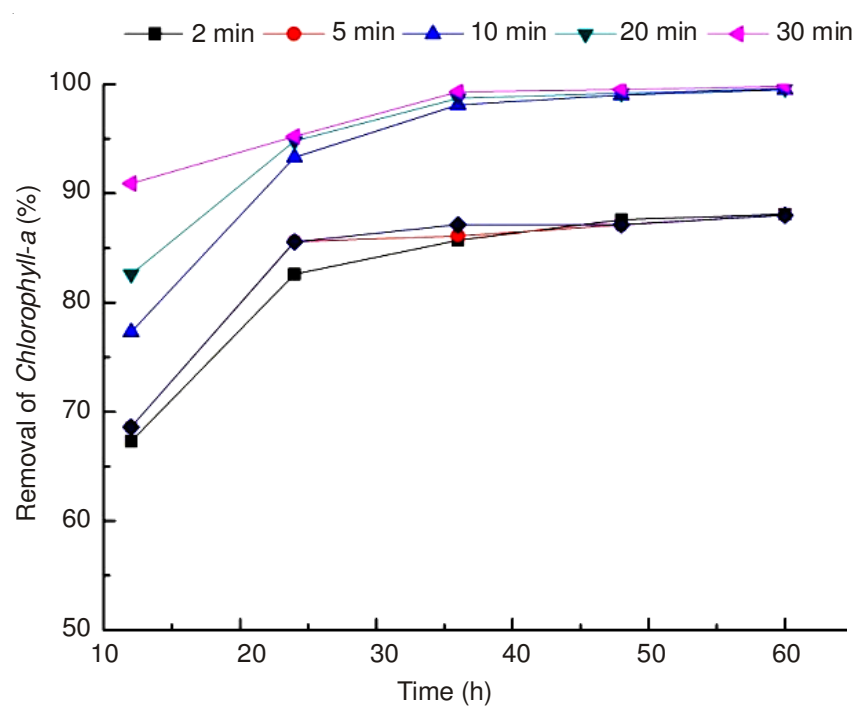

Fig. 5. Removal efficiencies of Microcystis aeruginosa at different ultrasonic irradiation time

This experiment also studied the effect of short irradiation time on Microcystis aeruginosa. Preparing six groups of 500 $\mathrm{mL}$ of Microcystis aeruginosa, one group was control group and the others were treated, respectively at 5, 15, 30 and $60 \mathrm{~s}$. Ultrasonic frequency, power density and temperature were set at $500 \mathrm{kHz}, 0.101 \mathrm{~W} / \mathrm{mL}$ and $20^{\circ} \mathrm{C}$. Each group repeated 3 times to ensure the credibility of the experiment. Fig. 6 is the changes of the concentration of Chlorophyll-a after sonication at different ultrasonic irradiation time. Fig. 7 shows the removal efficiencies of Microcystis aeruginosa.

In Fig. 7, the algae removal efficiencies were 70.5, 94.7, 96.2 and $98.8 \%$ at $5,15,30$ and $60 \mathrm{~s}$ after treatment for $36 \mathrm{~h}$. The parameter of $500 \mathrm{kHz}, 0.101 \mathrm{~W} / \mathrm{mL}$ and $5 \mathrm{~s}$ had significant effect on alga. The efficiency tended to saturation and Chlorophyll- $a$ started releasing when radiation time was higher than $15 \mathrm{~s}$.

Effect of different ultrasonic frequency on Microcystis aeruginos: Preparing 8 groups of $500 \mathrm{~mL}$ of Microcystis aeruginosa, one group was control group and the others were irradiating at 19.4, 40,89, 135, 157.9, 500 and $956 \mathrm{kHz}$

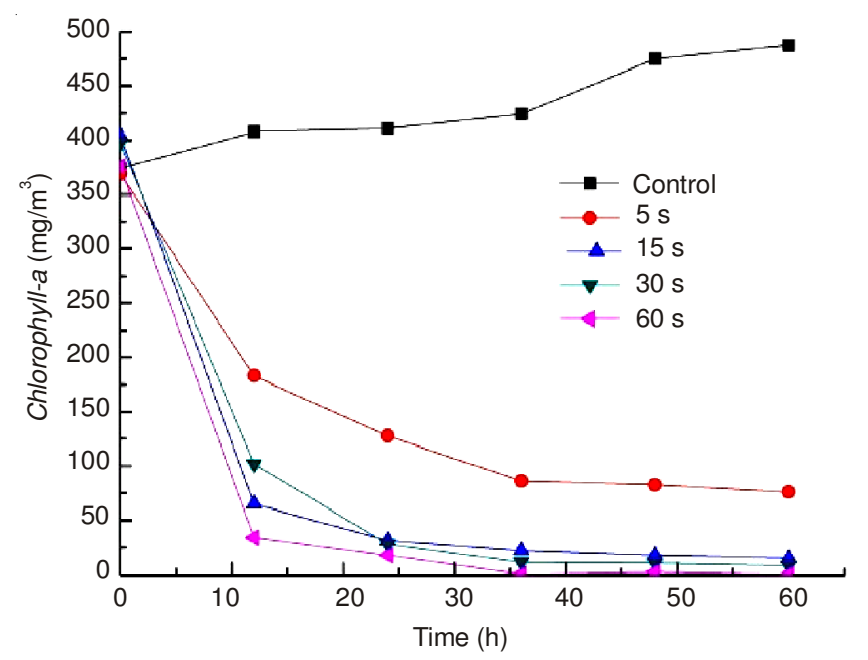

Fig. 6. Changes of the concentration of Chlorophyll-a after sonication at different short irradiation time 


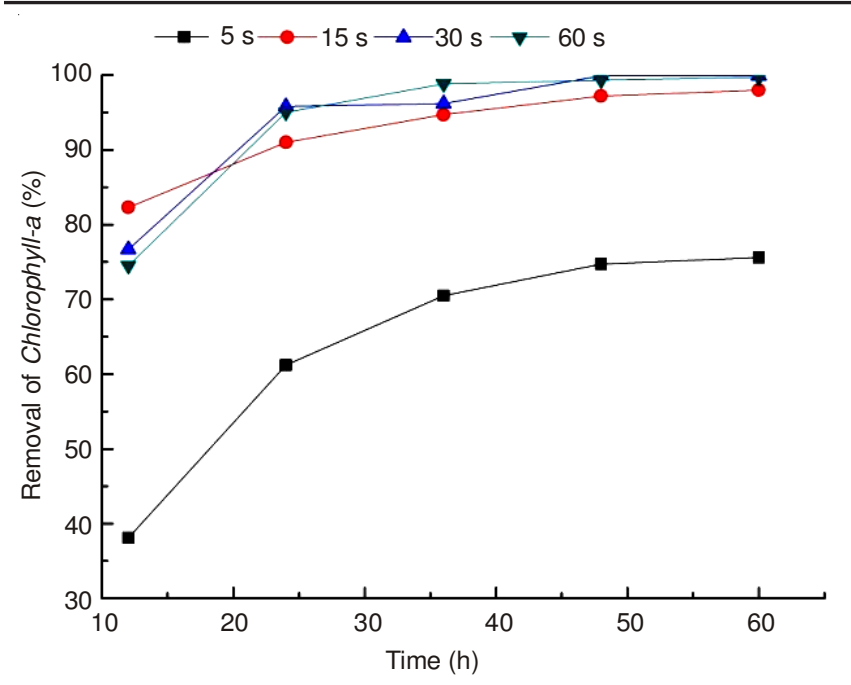

Fig. 7. Removal efficiencies of Microcystis aeruginosa at different short irradiation time

for $5 \mathrm{~min}$, respectively. Ultrasonic irradiation time and temperature were fixed at $5 \mathrm{~min}$ and $20^{\circ} \mathrm{C}$. Fig. 8 is the changes of the concentration of chlorophyll-a after sonication at different ultrasonic frequency. Fig. 9 shows the removal efficiencies of Microcystis aeruginosa.

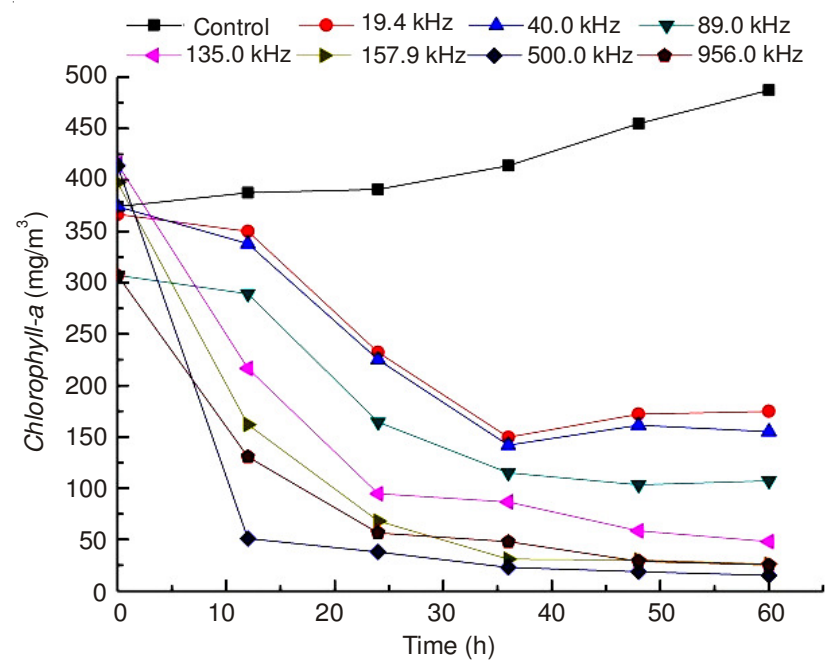

Fig. 8. Changes of the concentration of Chlorophyll-a after sonication at different ultrasonic frequency

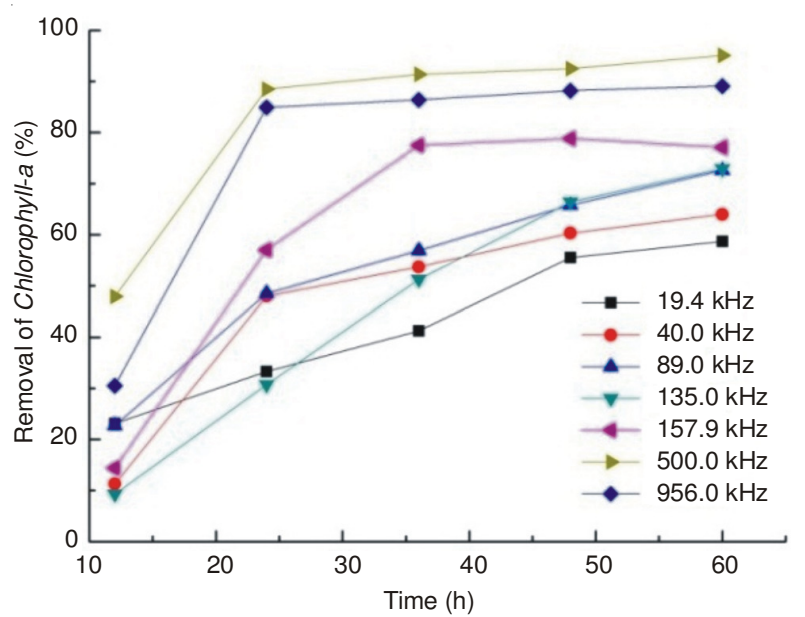

Fig. 9. Algae removal efficiencies of Microcystis aeruginosa at different ultrasonic frequency
In Fig. 9, the algae removal efficiency was 41.2, 53.7, $56.9,51.3,77.5,91.4$ and $86.4 \%$ after sonication for $36 \mathrm{~h}$. At a certain ultrasonic power, the algae removal efficiency increased with the increasing of frequency. The frequency of $500 \mathrm{kHz}$ had the best effect on Microcystis aeruginosa and the efficiency showed slight declines when the frequency was higher than $500 \mathrm{kHz}$. Higher frequency has stronger cavatition, producing more free radicals. Cavatition played the predominant role gradually rather than mechanical effect with frequency increasing. If frequency increases to a certain value, the cavatition tends to saturation and the efficiency reaches to top, that is specific algae species corresponding to a particular frequency.

Response surface design: The experiment of Microcystis aeruginosa removal by ultrasonic irradiation was based on the design principles of response surface method. It is designed by Box-Behnken Design model of the statistical software named Design Expert 7.1.3. Factors and levels design is shown in Table-1, where $X_{1}, X_{2}$ and $X_{3}$, respectively are ultrasonic frequency $(\mathrm{kHz})$, ultrasonic power density $(\mathrm{W} / \mathrm{mL})$ and ultrasonic irradiation time ( $\mathrm{min})$. Selected levels were boundary values and median of single factor results. Y respects the algae removal efficiency (\%) after being radiated for $36 \mathrm{~h}$, which is the assessment indicator. Combined experimental design factors and the results are shown in Table-2.

\begin{tabular}{lccccc}
\multicolumn{7}{c}{ TABLE-1 } \\
FACTORS AND LEVELS OF DESIGN \\
\hline Factor & Variable & Units & & Level \\
\hline Ultrasonic frequency & $\mathrm{X}_{1}$ & $\mathrm{kHz}$ & 400 & 600 & 800 \\
Ultrasonic power density & $\mathrm{X}_{2}$ & $\mathrm{~W} / \mathrm{mL}$ & 0.01 & 0.05 & 0.09 \\
Irradiation time & $\mathrm{X}_{3}$ & $\mathrm{~min}$ & 10 & 20 & 30 \\
\hline
\end{tabular}

\begin{tabular}{ccccccc}
\multicolumn{7}{c}{ MATRIX FOR HYBRID DESIGN WITH THE EXPERIMENT } \\
\cline { 1 - 6 } No. & \multicolumn{3}{c}{ Factor } & \multicolumn{3}{c}{ Y $(\%)$} \\
\cline { 2 - 6 } 1 & $\mathrm{X}_{1}$ & $\mathrm{X}_{2}$ & $\mathrm{X}_{3}$ & Measurement & Prediction & Error (\%) \\
2 & 400 & 0.01 & 20 & 75.32 & 76.35 & 1.4 \\
3 & 800 & 0.01 & 20 & 76.12 & 75.85 & 0.4 \\
4 & 800 & 0.09 & 20 & 88.6 & 88.87 & 0.3 \\
5 & 400 & 0.09 & 20 & 86.44 & 85.41 & 1.2 \\
6 & 800 & 0.05 & 10 & 77.47 & 75.16 & 3 \\
7 & 400 & 0.05 & 30 & 77.68 & 76.67 & 1.3 \\
8 & 800 & 0.05 & 30 & 78.44 & 80.75 & 1.2 \\
9 & 600 & 0.01 & 10 & 77.61 & 78.89 & 1.6 \\
10 & 600 & 0.09 & 10 & 88.91 & 90.96 & 2.3 \\
11 & 600 & 0.01 & 30 & 89.54 & 87.49 & 2.3 \\
12 & 600 & 0.09 & 30 & 98.77 & 97.49 & 1.3 \\
13 & 600 & 0.05 & 20 & 96.61 & 96.13 & 0.5 \\
14 & 600 & 0.05 & 20 & 94.54 & 96.13 & 1.7 \\
15 & 600 & 0.05 & 20 & 96.52 & 96.13 & 0.4 \\
16 & 600 & 0.05 & 20 & 96.48 & 96.13 & 0.4 \\
17 & 600 & 0.05 & 20 & 96.49 & 96.13 & 0.4 \\
\hline
\end{tabular}

Adaptive testing of model: Response surface regression was analyzed by using the function of adaptability analysis of Box-Behnken model of Design Expert. Design Expert includes linear polynomial model, quadratic polynomias model and cubic polynomial response model. Through simulating, modelling and comparing, we can get the best mathematical model. The result of adaptability analysis of different model is shown in Table-3. 


\begin{tabular}{|c|c|c|c|c|c|c|}
\hline \multicolumn{7}{|c|}{$\begin{array}{c}\text { TABLE-3 } \\
\text { SEQUENTIAL MODEL SUM OF SQUARES }\end{array}$} \\
\hline $\begin{array}{l}\text { Sources of } \\
\text { variation }\end{array}$ & $\begin{array}{l}\text { Sum of } \\
\text { squares }\end{array}$ & df & $\begin{array}{l}\text { Mean } \\
\text { square }\end{array}$ & F-value & $\begin{array}{c}\text { p-Value } \\
\text { (Prob } \\
>\text { F) }\end{array}$ & Note \\
\hline Mean vs. Total & 129000 & 1 & 129000 & & & \\
\hline Linear vs. Mean & 365.96 & 3 & 121.99 & 1.98 & 0.1673 & \\
\hline 2FI vs. Linear & 15.44 & 3 & 5.15 & 0.065 & 0.9770 & \\
\hline Quadratic vs. 2FI & 757.02 & 3 & 252.34 & 59.28 & $<0.0001$ & Suggested \\
\hline $\begin{array}{l}\text { Cubic vs. } \\
\text { Quadratic }\end{array}$ & 26.64 & 3 & 8.88 & 11.23 & 0.0204 & Aliased \\
\hline Residuals & 3.16 & 4 & 0.79 & & & \\
\hline Summation & 130100 & 17 & 7655.64 & & & \\
\hline
\end{tabular}

In Table-3, the results shows that quadratic polynomias model is more suitable, because $p$-value (Prob $>\mathrm{F}$ ) is less than $0.01 \%$, that is the adaptability responding to adapt of quadratic polynomias model is very significant. Only the $p$-values of Linear, 2 FI polynomias were less than $0.01 \%$, it can prove that they are more suitable than second order model to predict the response of the effect of ultrasound to Microcystis aeruginosa. The third order model appeared the phenomenon of confusion, so the method was not considered.

According to the results of lack of fit tests, it can be further proved that the quadratic model was more suitable for the response of the experiment. The analysis results are shown in Table-4.

\begin{tabular}{lcccccc}
\multicolumn{8}{c}{ TABLE-4 } \\
\multicolumn{7}{c}{ LACK OF FIT TESTS FOR BOX-BEHNKEN MODEL } \\
\hline \multicolumn{1}{c}{$\begin{array}{c}\text { Sources of } \\
\text { variation }\end{array}$} & $\begin{array}{c}\text { Sum of } \\
\text { squares }\end{array}$ & df & $\begin{array}{c}\text { Mean } \\
\text { Square }\end{array}$ & F-value & $\begin{array}{c}p \text {-Value } \\
(\text { Prob }>\text { F) }\end{array}$ & Note \\
\hline Linear & 799.10 & 9 & 88.79 & 112.30 & 0.0002 & \\
2FI & 783.66 & 6 & 130.61 & 165.19 & $<0.0001$ & \\
Quadratic & 26.64 & 3 & 8.88 & 11.23 & 0.0204 & Suggested \\
Cubic & 0.00 & 0 & & & & Aliased \\
Pure error & 3.16 & 4 & 0.79 & & & \\
\hline
\end{tabular}

The bigger the Prob $>\mathrm{F}$ value is, the better in terms of model. In Table-4, the Prob $>$ F value is less than 0.0001 both in linear and 2 FI polynomias, that is to say the possibilities of the $p$-value $(\operatorname{Prob}>\mathrm{F}$ ) less than 0.0001 are greater than F-value, therefore, these two models is not fit. The $p$-value (Prob $>\mathrm{F}$ ) of the second order model is 0.0204 that is significant $(<0.05)$ and the third order model arises confusion. Thus, the second order model is relatively appropriate.

Table 5 shows statistical analysis on the continuous model to further confirm the response of the model to the experiment.

\begin{tabular}{lcccccc}
\multicolumn{7}{c}{ TABLE-5 } \\
MODEL SUMMARY STATISTICS \\
\multicolumn{1}{c}{ Type } & Std. dev. & $\mathrm{R}^{2}$ & $\begin{array}{c}\text { Adjusted } \\
\mathrm{R}^{2}\end{array}$ & $\begin{array}{c}\text { Predicted } \\
\mathrm{R}^{2}\end{array}$ & Press & Note \\
\hline Linear & 7.86 & 0.3133 & 0.1548 & -0.0987 & 1283.55 & \\
2FI & 8.87 & 0.3265 & -0.0776 & -1.052 & 2397.18 & \\
Quadratic & 2.06 & 0.9745 & 0.9417 & 0.6310 & 431.12 & Suggested \\
Cubic & 0.89 & 0.9973 & 0.9892 & & \multicolumn{2}{c}{ Aliased } \\
\hline
\end{tabular}

In Table-5, the second order model has the smallest predicted $\mathrm{R}^{2}$ and the $\mathrm{R}^{2}$ of linear and $2 \mathrm{FI}$ polynomias is too small. The $\mathrm{R}^{2}$ of the second order model and the order third model are both higher than $95 \%$, but the latter appears confusion phenomenon. Consequently, the second order model more proper.

In conclusion, the second order model was choosing as the response regression model of removal efficiency.

Establishment of second order model and the analysis of variance: The second order model is an empirical model that describes the relationship between the independent variable (operating condition) and the response variable (dependent variable).

Use ultrasonic frequency $\left(\mathrm{X}_{1}\right)$, ultrasonic power density of $\left(\mathrm{X}_{2}\right)$ and ultrasonic irradiation time $\left(\mathrm{X}_{3}\right)$ as the independent variables and removal efficiency of Chlorophyll-a (Y) as response value to establish the quadratic regression model, showed as eqn. (2):

$$
\begin{aligned}
& \mathrm{Y}=-88.71+0.37 \mathrm{X}_{1}+391.17 \mathrm{X}_{2}+2.83 \mathrm{X}_{3}-0.09 \mathrm{X}_{1} \mathrm{X}_{2}+8.73 \times \\
& 10^{-4} \mathrm{X}_{1} \mathrm{X}_{3}-1.29 \mathrm{X}_{2} \mathrm{X}_{3}-2.93 \times 10^{-4} \mathrm{X}_{1}^{2}-1717.91 \mathrm{X}_{2}^{2}-0.047 \mathrm{X}_{3}^{2}
\end{aligned}
$$

Analyzing variance for the model to ensure the model can reflect the real surface and predict the Microcystis aeruginosa removal efficiency accurately. Results of variance analysis are in Table-6. Reliability analysis results of model are given in Table- 7 .

As the results shown in Tables-6 and 7, F-value is 29.71 and $p$-value (Prob $>\mathrm{F}$ ) is less than 0.0001 , achieving significant level, namely the model fits well in the whole regression area. Montgomery pointed out that the model test shall meet the following conditions: The F-value of lack of fit is greater than $0.1, \mathrm{R}^{2}$ is greater than 0.95 , the difference between Adjusted $\mathrm{R}^{2}$ and predicted $\mathrm{R}^{2}$ is less than $0.2, \mathrm{C} . \mathrm{V}$. is less than $10 \%$, Predicted $\mathrm{R}^{2}$ is greater than 0.7 and Adeq precision is greater than 4. Upon testing, all parameters of the quadratic regression equation model can meet the requirements of the above indicators.

\begin{tabular}{ccccccc}
\multicolumn{7}{c}{ TABLE-6 } \\
ANALYSIS OF VARIANCE OF THE REGRESSION EQUATION \\
\hline Source & $\begin{array}{c}\text { Sum of } \\
\text { Squares }\end{array}$ & df & $\begin{array}{c}\text { Mean } \\
\text { Square }\end{array}$ & F-value & $\begin{array}{c}p \text {-Value } \\
(\text { Prob }>\text { F) }\end{array}$ & Note \\
\hline Model & 1138.42 & 9 & 126.49 & 29.71 & $<0.0001$ & Significant \\
$\mathrm{X}_{1}$ & 7.84 & 1 & 7.84 & 1.84 & 0.2169 & Not significant \\
$\mathrm{X}_{2}$ & 243.43 & 1 & 243.43 & 57.18 & 0.0001 & Significant \\
$\mathrm{X}_{3}$ & 114.69 & 1 & 114.69 & 26.94 & 0.0013 & Significant \\
$\mathrm{X}_{1} \mathrm{X}_{2}$ & 2.19 & 1 & 2.19 & 0.51 & 0.4964 & Not significant \\
$\mathrm{X}_{1} \mathrm{X}_{3}$ & 12.18 & 1 & 12.18 & 2.86 & 0.1346 & Not significant \\
$\mathrm{X}_{2} \mathrm{X}_{3}$ & 1.07 & 1 & 1.07 & 0.25 & 0.6313 & Not significant \\
$\mathrm{X}_{1}{ }^{2}$ & 582.08 & 1 & 582.08 & 136.74 & $<0.0001$ & Significant \\
$\mathrm{X}_{2}{ }^{2}$ & 31.85 & 1 & 31.85 & 7.48 & 0.0291 & Significant \\
$\mathrm{X}_{3}{ }^{2}$ & 91.84 & 1 & 91.84 & 21.57 & 0.0024 & Significant \\
Residual & 29.80 & 7 & 4.26 & & & \\
Lack of Fit & 26.64 & 3 & 8.88 & 11.23 & 0.0204 & Significant \\
Pure error & 3.16 & 4 & 0.79 & & & \\
Cor total & 1168.22 & 16 & & & & \\
\hline
\end{tabular}

Table-7 shows that $\mathrm{R}^{2}=0.9745$, which means that the model has good correlation and can be used to the analysis and prediction of the removal process. The difference between adjusted $\mathrm{R}^{2}$ and predicted $\mathrm{R}^{2}$ is 0.0107 , less than 0.2 and C.V. value is $2.37 \%$, less than $10 \%$, indicating that credibility and precision of the experiment meets the requirements. Adeq precision is the ratio of effective signal and noise. The Adeq precision of this experiment is 14.114 that are higher than 4 , 


\begin{tabular}{|c|c|c|c|c|c|c|c|c|}
\hline \multicolumn{9}{|c|}{$\begin{array}{c}\text { TABLE-7 } \\
\text { MODEL RELIABILITY ANALYSIS }\end{array}$} \\
\hline Index & SD & Mean & C.V. (\%) & Press & $\mathrm{R}^{2}$ & Adjusted $\mathrm{R}^{2}$ & Predicted $\mathrm{R}^{2}$ & Adeq precision \\
\hline Results & 2.06 & 87.10 & 2.37 & 431.12 & 0.9745 & 0.9417 & 0.9310 & 14.114 \\
\hline
\end{tabular}

that is to say signal is strong enough to respond to the design. Significance test of regression coefficient in the quadratic regression model shows the $p$-value (Prob $>\mathrm{F}$ ) of $\mathrm{X}_{2}, \mathrm{X}_{3}, \mathrm{X}_{1}^{2}$, $\mathrm{X}_{2}^{2}, \mathrm{X}_{3}^{2}$ are all greater than 0.05 , having little effect on removal efficiency. The effect of power density was stronger than radiation time and frequency. The linear effect of $\mathrm{X}_{2}, \mathrm{X}_{3}$ on Microcystis aeruginosa was obvious and the surface effect of $\mathrm{X}_{1}^{2}, \mathrm{X}_{2}^{2}, \mathrm{X}_{3}^{2}$ was also obvious.

Response surface analysis of two-factor interaction effect: Mapping between any two of the factors, 3D plots and the contour plots were shown in Figs. 10 to 12. The change of removal efficiency can be directly seen from the color gradient.

Effect of ultrasonic frequency and ultrasonic power density: The effect of ultrasound frequency and ultrasound power density on the removal efficiency of Chlorophyll- $a$ and the interaction between the two factors is shown in Fig. 10.
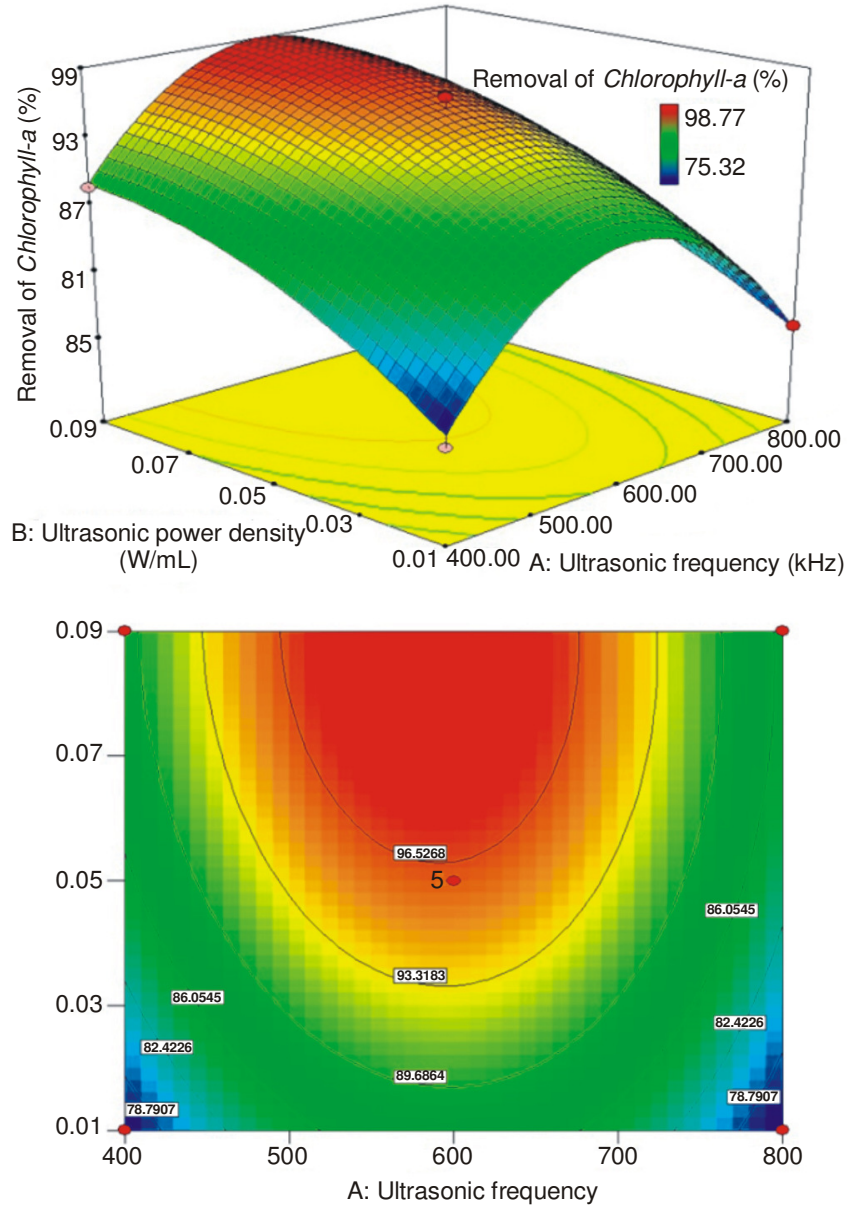

Fig. 10. Response surface plot and contour plots of algae control efficiencies by ultrasonic frequency and power density

Fig. 10 shows that, using ultrasound to control Microcystis aeruginosa, the removal efficiency increased first then decreased with the increasing of the frequency in the detection area. The optimum frequency is $600 \mathrm{kHz}$.
For ultrasonic power density, removal efficiency increased while volume density increasing. But when power density increased to a certain value, the rising trend is slow down gradually. In contour plot, contour thinning means the contribution of power volume density on the control efficiency becomes saturated. The removal efficiency reaches a maximum when the volume density is $0.9 \mathrm{~W} / \mathrm{mL}$ that is consistent with the results of single factor experiments.

If the shape of contour pot is oval, the interaction between the factors is significant, conversely circular. Accordingly, the interaction between ultrasonic frequency and ultrasonic power density is significant. The interaction performs in the increasing of removal efficiency with the increase of power density. When the efficiency reaches a limit value, its value is close to the optimum removal efficiency. There is a best volume density area, that is frequency is about 520 to $650 \mathrm{kHz}$ and volume density of ultrasonic power radiation is about 0.065 to 0.09 $\mathrm{W} / \mathrm{mL}$ because of the interaction. In this semi-elliptical area, the removal efficiency is more than $95 \%$.

Effect of ultrasonic frequency and irradiation time: The effect of ultrasound frequency and irradiation time on the removal efficiency of Chlorophyll-a and the interaction between the two factors is shown in Fig. 11.
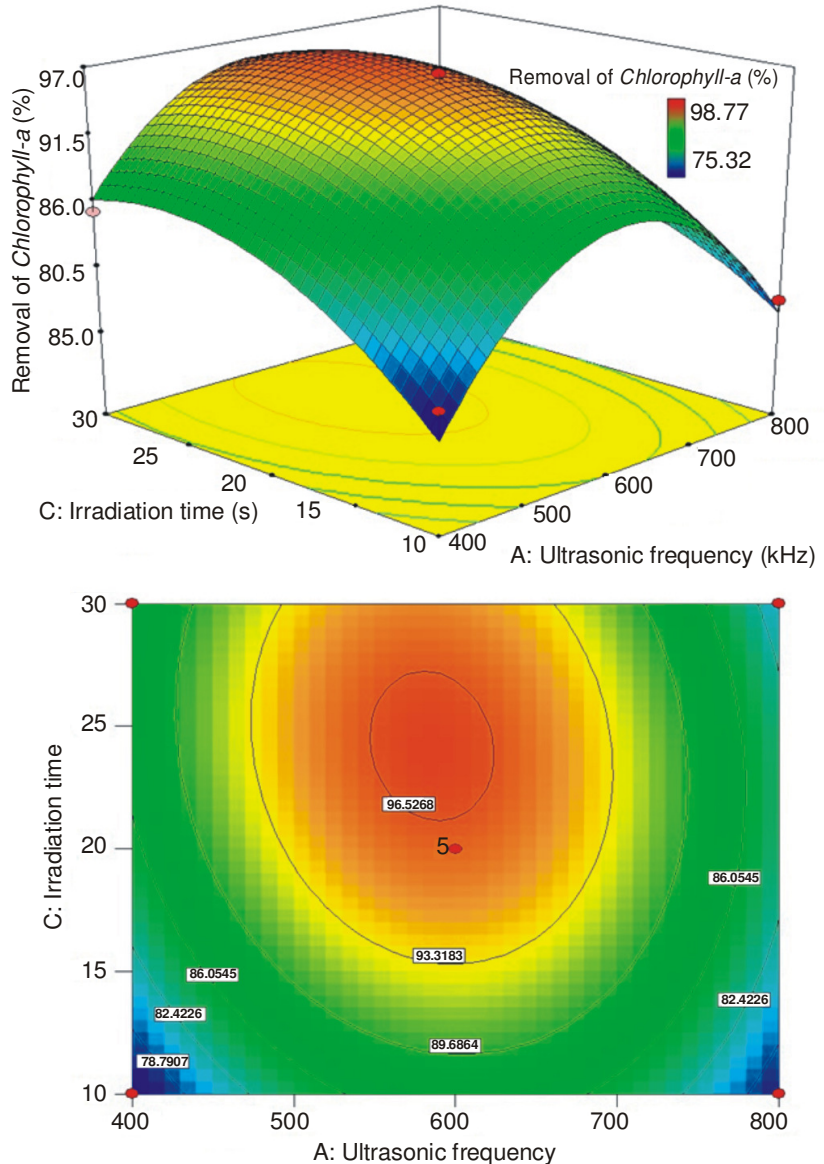

Fig. 11. Response surface plot and contour plots of removal efficiencies of algae density by ultrasonic frequency and irradiation time 
Fig. 11 shows that, using ultrasound to control Microcystis aeruginosa, the removal efficiency increased at first then decreased with the increasing of the frequency in the detection area. The optimum frequency is $600 \mathrm{kHz}$.

For irradiation time, removal efficiency increased while power density increased. But when power density increased to a certain value, the trend is slow down gradually. When all of the algae were damaged and algae density was minimal after cultivation of $36 \mathrm{~h}$, the radiation time is the optimum time. Treatment time keeping increasing, number of broken alga rose and cluster state of algae began to spread, leading to the rise in number of suspended particles, so does the detected number. The interaction between ultrasound frequency and irradiation time is not significant as seen from the control plot. In the area of 520 to $650 \mathrm{kHz}$ and 20 to $30 \mathrm{~s}$, the removal efficiency is more than $95 \%$.

Effect of ultrasonic power density and irradiation time: The effect of ultrasonic power density and ultrasound radiation time on the removal efficiency of chlorophyll-a and the interaction between the two factors are shown in Fig. 12.
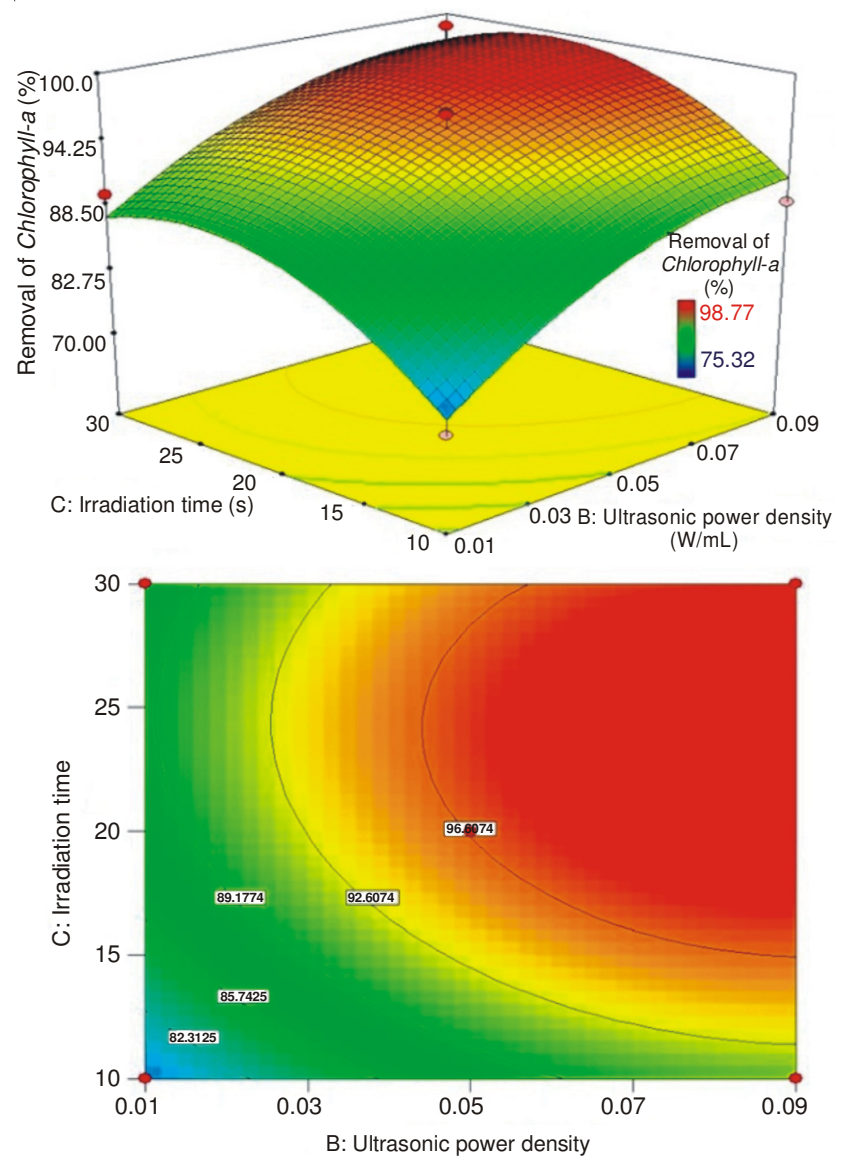

Fig. 12. Response surface plot and contour plots of algae control efficiencies by ultrasound irradiation time and power density

In Fig. 12, using ultrasound to control Microcystis aeruginosa, the removal efficiency increased at first then decreased with the increasing of the ultrasonic power density and irradiation time. In contour plot, contour thinning means the contribution of the power density and irradiation time on the control efficiency becomes saturated gradually, that is basically identical with the conclusion in preceding context.
The interaction between the power density and irradiation time is significant as seen from the control plot. When radiation time is close to the optimal value, algae removal efficiency is also close to the optimum. There is a best volume density area, irradiation time is about 20 to $30 \mathrm{~s}$ and power density is about 0.065 to $0.09 \mathrm{~W} / \mathrm{mL}$. In this semi-elliptical area, the removal efficiency is more than $95 \%$. It can also be seen from contour map is that the influence of power density on algae is greater than irradiation time.

Therefore, descending order of the effect on removal efficiency is: Ultrasonic power density $>$ ultrasonic irradiation time $>$ ultrasonic frequency.

Determination and validation of the optimal conditions: Through calculating the partial differentiation of the established second order regression model, the maximum removal efficiency of algae and optimal parameter combination can be obtained. And the reliability of response surface models was proved by experimental verification of the optimal value.

Determination of the optimal conditions: Regression equation can be written as eqn. (3):

$$
\mathrm{Y}=\mathrm{a}+\mathrm{X}^{\mathrm{T}} \mathrm{b}+\mathrm{X}^{\mathrm{T}} \mathrm{cX}
$$

In which:

$$
X=\left[X_{1}, X_{2}, X_{3}\right]^{T}
$$

Firstly,

$$
\frac{\partial Y}{\partial X}=0
$$

Equal to: $\frac{\partial Y}{\partial X}=\left[\frac{\partial Y}{\partial X_{1}}, \frac{\partial Y}{\partial X_{2}}, \frac{\partial Y}{\partial X_{3}}\right]=0$

After implementing, the eqn. (7) is

$$
\left(\begin{array}{ccc}
5.9 \times 10^{-4} & 0.093 & 8.7 \times 10^{-4} \\
0.093 & 3437.81 & 1.29 \\
8.7 \times 10^{-4} & 1.29 & 0.093
\end{array}\right) \cdot\left(\begin{array}{l}
X_{1} \\
X_{2} \\
X_{3}
\end{array}\right)=\left(\begin{array}{l}
0.37 \\
391.17 \\
2.83
\end{array}\right)
$$

The solution is: $X_{1}=580, X_{2}=0.089, X_{3}=24$.

That is to say, the optimal condition for the Microcystis aeruginosa removal is ultrasound frequency of $580 \mathrm{kHz}$, ultrasonic power density of $0.089 \mathrm{~W} / \mathrm{mL}$, irradiation time of $24 \mathrm{~s}$.

Verification of the model: In order to verify the prediction results, the reaction conditions was the ultrasonic frequency of $580 \mathrm{kHz}$, ultrasonic power volume density of $0.089 \mathrm{~W} / \mathrm{mL}$, irradiation time of $24 \mathrm{~s}$. Taking three groups to test, the average of removal efficiency was $(99.33 \pm 0.02) \%$. Comparing the result of verification experiments with predicted maximum of $99.58 \%$, the error was only $0.25 \%$. Therefore, the model does have some practical value for the accurate analysis and forecasting of ultrasonic parameters of Microcystis aeruginosa removal.

\section{Conclusion}

The experiment of the effect of different ultrasonic power density shows that, the higher the volume density, the better efficiency is. When the volume density reaches a certain value, efficiency tends to be saturated. Low power density ultrasound (lower than threshold value) mainly inhibits Microcystis aeruginosa by mechanical action and the effect was modest, because the damage can be fixed. However, high intensity ultrasound (higher than threshold value) that could cause 
cavitation and mechanical action, and cavitation was dominant effect that can damage algae cells permanently.

Long irradiation time of high intensity ultrasound has negative impacts on the treatment and it is uneconomical. The key thing is to choose an appropriate radiation time in application. The parameter of $500 \mathrm{kHz}, 0.101 \mathrm{~W} / \mathrm{mL}$ and $5 \mathrm{~s}$ had significant effect. $15 \mathrm{~s}$ was the optimum irradiation time, but the efficiency tended to saturation and chlorophyll-a started releasing when radiation time was higher than $15 \mathrm{~s}$.

The frequency of $500 \mathrm{kHz}$ had the best effect on Microcystis aeruginosa at $0.014 \mathrm{~W} / \mathrm{mL}$ and the efficiency had slight declines when the frequency was higher than $500 \mathrm{kHz}$. With the increasing of ultrasonic frequency, cavitation became dominant position from mechanical effect gradually.

Using quadratic polynomial regression model of response surface method for optimization in ultrasonic frequency, power density and irradiation time, the optimal parameters combination are: ultrasonic frequency of $580 \mathrm{kHz}$, ultrasonic power density of $0.089 \mathrm{~W} / \mathrm{mL}$, irradiation time of $24 \mathrm{~s}$. Predicted maximal removal efficiency was $99.58 \%$ that was close to the experimental value of $(99.33 \pm 0.02) \%$. The error was only $0.25 \%$, proving that the model can be used to forecast the effect of ultrasonic on Microcystis aeruginosa.

\section{ACKNOWLEDGEMENTS}

This work was financially supported by the National Natural Science Foundation of China (51308123), the Scientific research
Foundation in Fuzhou University (2013-XY-25) and Fund for Fostering Talents of Fuzhou University (XRC-1266).

\section{REFERENCES}

1. D.J. Conley, H.W. Paerl, R.W. Howarth, D.F. Boesch, S.P. Seitzinger, K.E. Havens, C. Lancelot and G.E. Likens, Science, 323, 1014 (2009).

2. J.H. Shao, Z.X. Wu, G.L. Yu, X. Peng and R. Li, Chemosphere, 75, 924 (2009).

3. I. Stewart, P.J. Schluter and G.R. Shaw, Environ. Health, 5, 7 (2006).

4. P. Banaszuk, A. Wysocka-Czubaszek and A.K. Kamocki, Ecol. Eng., 37, 260 (2011).

5. H.K. Hudnell, Toxicon, 55, 1024 (2010).

6. C.Y. Ahn, M.H. Park, S.H. Joung, H.S. Kim, K.-Y. Jang and H.-M. Oh, Environ. Sci. Technol., 37, 3031 (2003).

7. T.J. Lee, K. Nakano and M. Matsumara, Environ. Technol., 22, 383 (2001).

8. S. Broekman, O. Pohlmann, E.S. Beardwood and E.C. de Meulenaer, Ultrason. Sonochem., 17, 1041 (2010).

9. G. Fan, Z. Zhang, J. Luo, Q. Lin and L. Chen, Asian J. Chem., 26, 1165 (2014).

10. W.B. McNamara III, Y.T. Didenko and K. S. Suslick, Nature, 401, 772 (1999).

11. G. Fan, Z. Zhang, J. Luo, X. Wan and C. Liu, Asian J. Chem., 25, 202 (2013).

12. X. Wu, E.M. Joyce and T.J. Mason, Water Res., 46, 2851 (2012).

13. X. Wu, E.M. Joyce and T.J. Mason, Harmful Algae, 10, 738 (2011).

14. W.-B. Chu, J.-W. Yang, T.-J. Liu, C. Tiu and J. Guo, Colloids Surf. A, 302, 1 (2007).

15. H. Hao, M. Wu, Y. Chen, J. Tang and Q. Wu, Colloids Surf. B, 33, 151 (2004).

16. G. Fan, D. Liu and G. Zhu, Q. Lin and L. Chen, Desalin. Water Treat.; doi:10.1080/19443994.2014.893542. 